\title{
La base de datos del Patrimonio Inmueble de Andalucía en Internet: BDI-PHA
}

\begin{abstract}
Resumen
De acuerdo con la línea iniciada desde hace varios años por el Centro de Documentación del IAPH de transferencia de la información del Patrimonio Histórico, se presenta la base de datos del Patrimonio Inmueble de Andalucía (BDI-PHA), incluida en el Servidor Web del IAPH en 200I. Se analizan las ventajas de una aplicación integrada de consulta para todo el Patrimonio Inmueble de Andalucía, los problemas surgidos al integrar información procedente de tres bases de datos diferentes: SIBIA, ETNO y DatARQUEOS, así como los contenidos y estructura de la nueva base de datos. Para finalizar se comentan brevemente las perspectivas de futuro para cualificar la aplicación.
\end{abstract}

\section{Palabras clave}

Bases de datos / Patrimonio Inmueble / Andalucía / Internet / Servidor Web / IAPH / Patrimonio Arquitectónico / Patrimonio Arqueológico / Patrimonio Etnológico / SIBIA / ETNO / DatARQUEOS/ Sistema de Información del Patrimonio Histórico /

\section{Introducción}

Desde que a finales de 1990 se inicia la puesta en marcha del Sistema de Información del Patrimonio Histórico de Andalucía, éste ha pasado por distintas etapas, tras un primer periodo en el que el objetivo fundamental era la producción y el desarrollo de la información a través de la creación de las diferentes bases de datos de Patrimonio Histórico, se inicia, a partir de 1995, una línea de transferencia de la información del Patrimonio Histórico. Para ello se ponen en marcha distintos Servicios de Información', con objeto de hacer accesible la información de Patrimonio Histórico a la Administración, los investigadores y el público en general, se desarrolla un Servidor Web ${ }^{2}$ y se elaboran diferentes productos digitales sobre información contenida en las diferentes bases de datos de Patrimonio Histórico ${ }^{3}$.
El Servidor Web del IAPH desde su puesta en marcha en 1996 ha combinado información institucional con información temática de Patrimonio Histórico. Inicialmente se incluyó principalmente información general relativa al IAPH e información específica de la organización y funciones de cada uno de los departamentos y centros de esta institución. Además de esta información institucional, se han ido incorporado progresivamente una serie de puntos informativos temáticos que se consideran de vital importancia, en cuanto que aglutinan una información directa, viva, original y atractiva en el campo del Patrimonio Histórico, con especial incidencia en el ámbito andaluz. Hasta el momento se han desarrollado las secciones que se comentan a continuación.

Patrimonio Histórico Andaluz, con información de los (B.I.C.), Conjuntos Históricos, Docomomo. Patrimonio de la Humanidad, Catedrales, Itinerarios y Cementerios, referidos en la actualidad sólo al patrimonio arquitectónico de Granada. Este apartado informativo está pendiente de ampliación geográfica y temática.

Productos Culturales, contiene diferentes productos informativos (Velázquez-IV Centenario, Clausuras de Cádiz, Itinerario cultural de Málaga urbana, Docomomo, Intervenciones Experimentales), así como las bases de datos de PH.

Publicaciones, incluye las publicaciones del $\mathrm{IAPH}$, con los índices del Libro $X^{\circ}$ Aniversario del IAPH, de las colecciones Cuadernos y Cuadernos Técnicos y del PH Boletín del Instituto Andaluz del Patrimonio Histórico, así como los dossiers temáticos $\mathrm{PH}$ a texto completo y los formularios electrónicos de suscripción.

Agenda de Formación, ofrece la oferta formativa en el campo del Patrimonio Histórico en el ámbito andaluz, nacional e internacional, relativo al programa de formación anual del IAPH, cursos de postgrado en materia de Patrimonio en España y cursos y jornadas en España y en el extranjero, así como las convocatorias de becas del IAPH. 
Actividades Culturales, presenta las actividades que en materia de cultura se realizan en las distintas instituciones de Andalucía, tales como las actividades de la Consejería de Cultura recogidas en el Boletín mensual de Actividades Culturales y las estadísticas culturales, y actividades de ayuntamientos, diputaciones, fundaciones, asociaciones, etc.

Webs de interés, ofrece el acceso a otros servidores nacionales e internacionales, institucionales y temáticos, especializados en diferentes aspectos del patrimonio histórico: arquitectura, conservación, arqueología, museos, historia del arte, bibliotecas, documentación e información, universidades, investigación, etc.

Buscadores de Información, contiene enlaces a buscadores, directorios y portales nacionales e internacionales, para posibilitar el acceso a herramientas generales de búsqueda.

El apartado Bases de Datos del Patrimonio Histórico, (incluido en la sección Productos Culturales) se inicia en 1999 con la incorporación al Servidor Web del IAPH de la información contenida en algunos de los módulos de la base de datos del Patrimonio Arqueológico de Andalucía (ARQUEOS) ${ }^{4}$. Nace con el objetivo de facilitar a los usuarios de Internet el acceso a una información básica del Patrimonio Histórico Andaluz y para ello se prevé, desde el principio, la incorporación progresiva de las diferentes bases de datos que sobre Patrimonio Histórico inmueble y mueble estaba desarrollando el Centro de Documentación del IAPH.

En la actualidad, y este es el objeto de este artículo, se presenta un nuevo desarrollo informático que incorpora en Internet información de todo el Patrimonio Inmueble de Andalucía.

\section{La nueva aplicación: Avances, conteni- dos y estructura}

\section{Avances}

$\mathrm{BDI}$-PHA es una base de datos que contiene un conjunto integrado de información relativa a los elementos del Patrimonio Inmueble de Andalucía. Con la incorporación de la BDI-
PHA en Internet se pretende ofrecer un servicio interactivo del Patrimonio Histórico a los ciudadanos, mejorando la transferencia y facilitando el conocimiento de la información patrimonial, sin barreras espaciales ni temporales.

Este desarrollo informático incorpora distintas novedades con respecto a la anterior aplicación. En primer lugar se trata de una aplicación integrada que recoge una información básica de todo el Patrimonio Inmueble, y permite consultas de tipo general sobre todo el Patrimonio Inmueble de Andalucía y consultas específicas sobre Patrimonio Arqueológico, Arquitectónico y Etnológico.

La aplicación que presentamos representa un primer avance en la línea de trabajo que hacia la integración de las diferentes bases de datos de Patrimonio en un único Sistema, inició el Centro de Documentación hace ya algún tiempo ${ }^{5}$. El Sistema Integrado permitirá el análisis de un mismo bien desde las distintas vertientes patrimoniales y favorecerá la carga y el acceso a toda la información del Patrimonio Histórico desde los distintos organismos relacionados con el Patrimonio Histórico.

BDI-PHA incorpora un formulario de búsqueda común que permite realizar consultas de tipo general como por ej. todo el Patrimonio Inmueble protegido de una ciudad, o el Patrimonio Inmueble de un determinado Periodo Histórico o Tipología, sin necesidad de realizar búsquedas parciales en las distintas bases de datos. También incluye formularios de búsqueda específicos que permiten consultas más exhaustivas sectoriales para los distintos tipos de Patrimonio Inmueble o Caracterizaciones: Patrimonio Arqueológico, Arquitectónico y Etnológico.

Otra novedad es la incorporación de un módulo de búsquedas predeterminadas, de acuerdo con aquellas peticiones de información más frecuentes recibidas en el servicio de información. La aplicación incluye también distintos tipos de informes de salida que incorporan la imagen de los bienes seleccionados ${ }^{6}$.

Por último, comentaremos algunos de los problemas planteados previos a la incorporación de la aplicación a Internet y que son el resultado de agrupar información que aún está en proceso de integración. Es decir, antes de culminarse el Sistema Integrado de Patrimonio Histórico, se ha desarrollado una aplicación que a un nivel básico integra dicha información, información que en la actualidad está en bases de datos sectoriales elaboradas en momentos distintos y por lo tanto con criterios en algunos casos diferentes. Ha sido necesario, por este motivo, resolver algunas deficiencias para que la consulta y la visualización integrada de la información fuera posible. Por ejemplo, en la base de datos Arqueos los campos Tipologías y Períodos Históricos están vinculados, es decir, en el caso de yacimientos que presentan una secuencia cronológica amplia y tipologías múltiples, cada una de ellas va asociada a su período histórico correspondiente. Sin embargo en la base de datos Sibia estas informaciones, de momento, no están vinculadas ${ }^{7}$, lo que ha originado algunos problemas de integración.

El desarrollo de bases de datos sectoriales por disciplinas patrimoniales conlleva el posible duplicado de registros, pues un mismo bien puede ser analizado desde un punto de vista arqueológico, arquitectónico o etnológico. Aunque está previsto resolver este problema con el Sistema Integrado, mientras tanto para la presentación de esta información en Internet y evitar que de un mismo bien aparecieran dos registros diferentes, se han seleccionado aquellos que estaban más completos.

Las bases de datos sectoriales tienen listados asociados normalizados en los campos de Tipologías, Periodos Históricos, Actividades, etc. Aunque todos estos listados han sido normalizados de acuerdo con el Tesauro de Patrimonio Histórico ${ }^{8}$ existían diferencias sectoriales, por lo que ha sido necesario depurarlos e integrarlos para evitar errores al realizar la consulta integrada.

\section{Contenidos}

Con la implantación de esta aplicación en el Servidor Web del IAPH cualquier usuario puede acceder a una información básica de las tres bases de datos del SIPHA relacionadas con el Patrimonio Inmueble de Andalucía: la base de datos del Patrimonio Arquitectónico (SIBIA), del Patrimonio Arqueológico (ARQUEOS, en la actualidad DatARQUEOS) y del Patrimonio Etnológico (ETNO). 
La base de datos de Patrimonio Arquitectónico (SIBIA) contiene información referida a los Monumentos, Jardines Históricos y Sitios Históricos de Andalucía. Cuenta con unos 4000 registros, relativos a bienes protegidos y de interés?

Esta base de datos se diseñó y desarrolló durante 1994 y 1995 y desde entonces su alimentación se concibió desde dos líneas de actuación. Por un lado, a través de la informatización de la información ya existente sobre el Patrimonio Arquitectónico en las fuentes documentales propias de los Servicios de Protección y Conservación de la DGBC, así como a través del seguimiento de las nuevas declaraciones y procesos administrativos llevados a cabo desde la DGBC. Por otra parte, el Plan Sectorial de Patrimonio Arquitectónico establece múltiples trabajos y subvenciones a investigaciones encaminados a completar la información de módulos informáticos, basados en la recopilación de información documental, bibliográfica y trabajo de campo. De esta manera se está procediendo a la georreferenciación de los edificios urbanos y dispersos, a la informatización de distintos inventarios andaluces y a la recogida de las determinaciones de planeamiento sobre los mismos.

En la actualidad desde Internet puede accederse a todos los bienes protegidos, incoados, declarados BIC e inscritos en el Catálogo Andaluz de Patrimonio Histórico, con excepción de la arquitectura defensiva (fortificaciones $y$ torres) ${ }^{10}$.

La base de datos de Patrimonio Arqueológico (DatARQUEOS) incluye información sobre los yacimientos arqueológicos andaluces y su distribución en el medio físico. En la actualidad, la base cuenta con 12000 registros de todas las provincias andaluzas, con información procedente, entre otras fuentes, del Inventario de Yacimientos Arqueológicos de Andalucía, de los expedientes para la inscripción de zonas Arqueológicas en el Catálogo General del Patrimonio Histórico de Andalucía, las intervenciones arqueológicas, fichas diagnóstico, etc".

Desde que en 1995 se comenzara a trabajar en el Área de Arqueología, se han emprendido diversas líneas de trabajo, algunas de ellas en colaboración con otras instituciones y organismos. Entre estas últimas destaca la colaboración con el Centro de Arqueología Subacuática en la elaboración de la Carta de Riesgo Antrópico del Patrimonio Arqueológico Subacuático, y la colaboración con la Dirección General de Bienes Culturales y las Delegaciones Provinciales de Cultura en las campañas de actualización y revisión del Inventario de Yacimientos Arqueológicos de Andalucía.

A la información contenida en DatARQUEOS se puede acceder a través de Internet desde 1999. En la actualidad es posible consultar esta información conjuntamente con el resto del Patrimonio Inmueble de Andalucía y de forma sectorial. La nueva aplicación incorpora como novedad con respecto a la anterior, más información sobre el Patrimonio Arqueológico protegido.

\section{La base de datos de Patrimonio Etnológico} (ETNO) incluye información de bienes inmuebles de interés etnológico procedente del Inventario de Bienes Etnológicos y otras fuentes ${ }^{12}$. Cuenta con unos 4000 registros de diferentes tipologías, como edificios industriales, agropecuarios, viviendas y espacios de sociabilidad. En la actualidad está en proceso de normalización e informatización. A través de Internet es posible acceder a una información básica de todos los bienes incluidos en la base de datos ETNO, además de una información completa de los bienes localizados en la provincia de Málaga ${ }^{13}$.

Todas estas bases de datos están estructuradas en diferentes módulos de información: identificación, descripción, localización, planeamiento, conservación, análisis formal, análisis funcional, documentación, etc., de los cuales se ha extraído una información básica consultable a través de Internet.

\section{Herramientas y Estructura}

La aplicación informática que permite realizar consultas a la BDI-PHA se ha desarrollado con herramientas de última tecnología. Emplea tecnología Java para la parte del Servidor, utilizando servlets para acceder a una base de datos MySQL. En la parte cliente permite consultar distintos campos de la base de datos mediante formularios HTML que también emplean Javascript para agilizar la velocidad de la carga de las páginas. Todo ello funciona sobre sistema operativo Solaris I0 en un servidor Sun UltraSparc 4.

A la aplicación se puede acceder desde la página principal del Servidor Web del IAPH <http://www.iaph.junta-andalucia.es> que contiene un enlace directo a la base de datos BDI-PHA <http://www.iaph.juntaandalucia.es/BBDD.html>. Asimismo también se puede acceder a partir del apartado Productos Culturales, y desde la página del Centro de Documentación.

Desde la página de entrada puede accederse a la presentación de los contenidos, a unas instrucciones de ayuda para el correcto desarrollo de la consulta (búsqueda por palabras, operadores booleanos, contenidos de campos...), y a los distintos modos de búsqueda: libre y rápida (Pantalla I)

Para realizar la Búsqueda se ofrecen dos posibilidades:

- Búsqueda Libre: permite al usuario realizar una búsqueda "a la carta", es decir, seleccionar los módulos, campos, términos, etc. que considere más idóneos para su consulta de una forma abierta y flexible.

- Búsqueda Rápida: esta modalidad alternativa presenta, por el contrario, una serie de opciones predeterminadas que responden a la agilización de "consultas-tipo", establecidas de acuerdo con el tipo de demandas más frecuentes recibidas en el servicio de información.

La Búsqueda Libre presenta un marco inicial para la selección de una de las tres opciones o modalidades por separado o de forma conjunta.

\section{Caracterización}

- Todas

- Patrimonio Arquitectónico

- Patrimonio Arqueológico

- Patrimonio Etnológico 
A partir de esta selección previa aparece el Formulario de búsqueda correspondiente. Si se elige una sola opción encontramos un formulario con los campos específicos de dicha modalidad, y si se elige la posibilidad de consultar todas simultáneamente encontramos los campos básicos comunes de las tres caracterizaciones (Pantalla 2)

Los formularios incluyen los nombres de los campos que despliegan una ventana explicativa con la descripción básica del campo, y una línea para la cumplimentación de los términos de búsqueda. Algunos de los campos (provincia, municipio, tipologías, actividades, períodos históricos y datos de protección) tienen asociados listados de términos que pueden capturarse para realizar la consulta.

Además entre los campos existe la posibilidad de combinación de operadores booleanos $(Y$, $\mathrm{O}, \mathrm{NO}$ ), y al final del formulario se presenta la utilidad de buscar por todas las palabras (en cualquier orden), todas las palabras (en orden), cualquier palabra, y frase exacta.

La opción de Búsqueda Rápida presenta varias posibilidades de búsquedas predeterminadas, consideradas como las consultas tipo más usuales:

- Código del Bien: permite obtener la información sobre un bien concreto de una forma rápida mediante la cumplimentación del código del bien.

- Bienes Culturales: tiene como finalidad la recuperación de un bien concreto a través de la selección de la caracterización y de los datos de provincia, municipio y denominación del bien.

- Geográfica: permite buscar y recuperar la información de todos los bienes de una provincia y/o municipio, previa selección de la caracterización.

- Protección: permite buscar los bienes a través de los datos de protección y referidos o no a una provincia determinada, con la posibilidad de especificar la caracterización.

En cuanto a la Recuperación de la información, una vez efectuada la búsqueda, libre o rápida, se presentan los resultados de la bús-

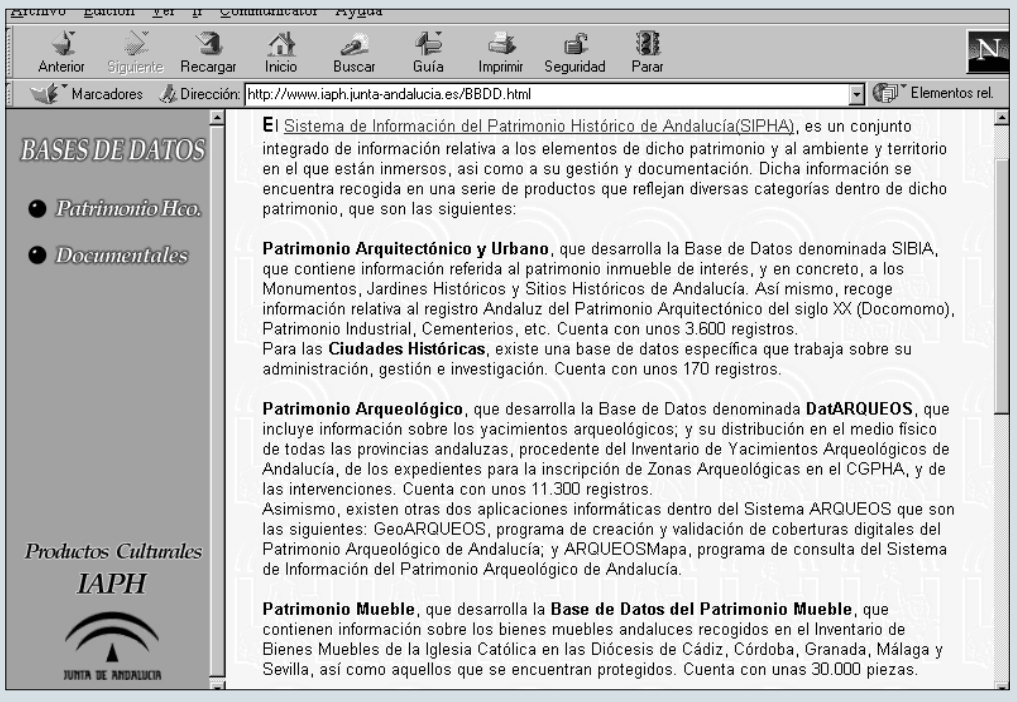

Pantallas I, 2 y 3.

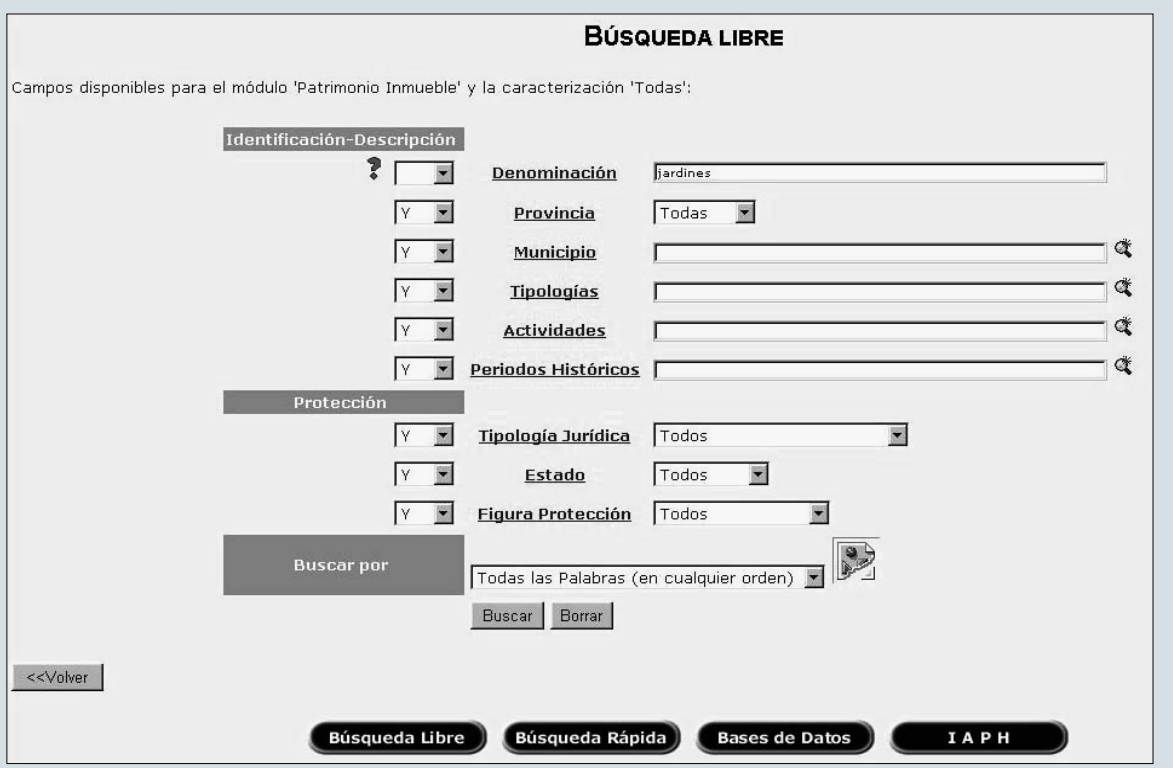

REsULTAdos DE LA BÚSQUEDA

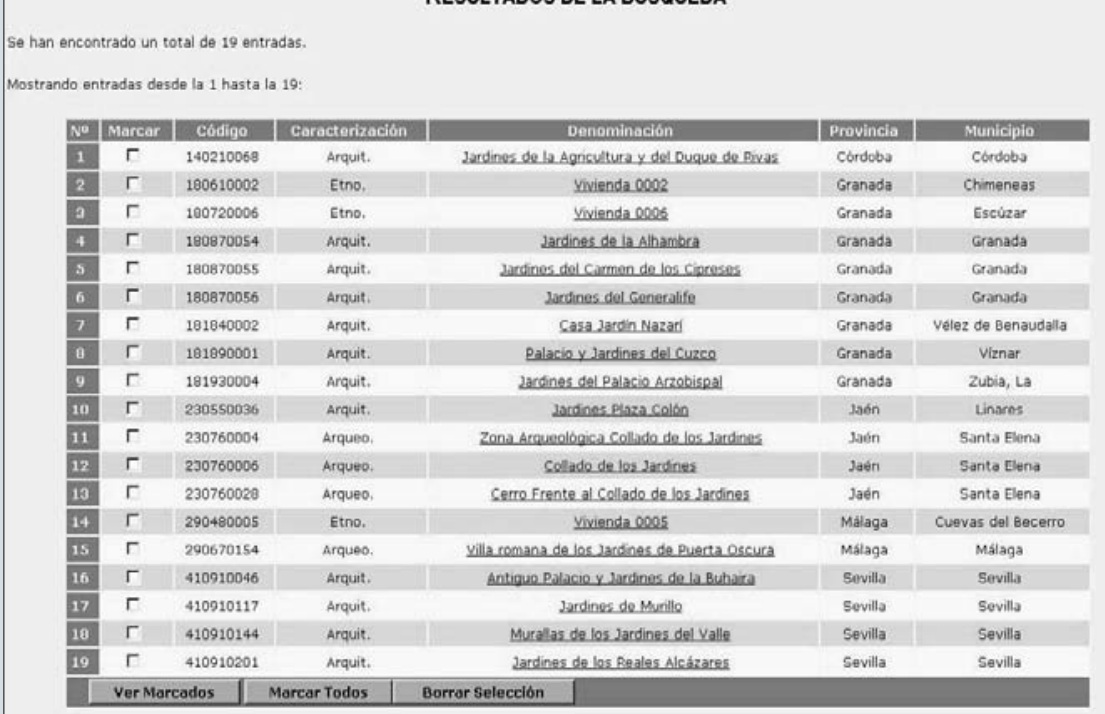



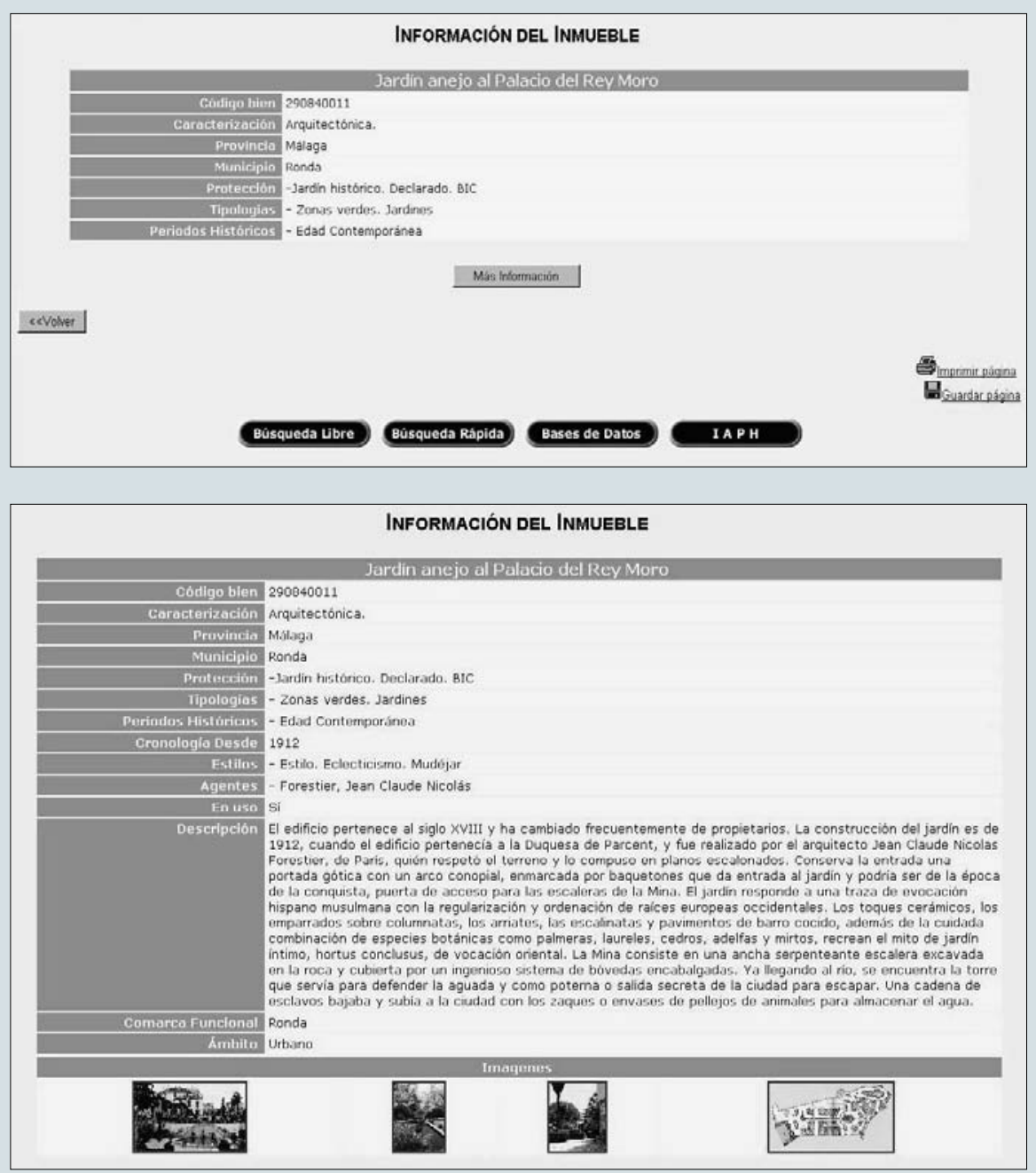

Pantallas 4 y 5 .

queda con indicación del número total de registros recuperados y los campos básicos identificativos (código, caracterización, denominación, provincia y municipio). (Pantalla 3).

En la Lista de Resultados tenemos la opción de marcar uno o varios registros de nuestro interés o marcar todos, con la posibilidad de ver sólo los marcados. Asimismo podemos visualizar un bien concreto de la lista a través del enlace hipertextual contenido en la denominación. Es decir, se pueden ver todos los registros de un modo secuencial (de uno en uno) o ver únicamente aquellos registros seleccionados o marcados.

Una vez seleccionados los registros se visualizará, por defecto, una información básica, desde la cual se puede accionar la opción Más Información, que nos permite visualizar una información más completa.
El Informe Básico de salida es común para todas las caracterizaciones y tipos de búsqueda, que presenta todos los campos de Identificación-Descripción del Bien que disponga de información de pública consulta en las bases de datos de origen ( Pantalla 4)

La opción Más información presenta un informe de salida común más completo que además de datos de Identificación-Descripción incorpora información de Localización, Protección e incluso Imágenes del Bien seleccionado, que pueden activarse y ampliar su visualización (Pantalla 5).

Finalmente, cabe destacar las posibilidades de imprimir, de guardar la información seleccionada, así como de volver al punto de partida o a la página principal del IAPH para consultar otras informaciones y contenidos disponibles.

\section{Perspectivas de futuro}

El desarrollo actual de la BDI-PHA supone una primera fase de la aplicación de consulta de la base de datos Integrada del Patrimonio Histórico de Andalucía a través de Internet. Por tanto, no es un proyecto cerrado. El objetivo general es completar la información existente y cualificar la aplicación actualmente en consulta, con el fin de posibilitar un interfaz único, fácil y completo a la información del Patrimonio Histórico Andaluz, a través de nuevos medios de comunicación de cobertura mundial.

Los objetivos específicos planteados a corto y medio plazo se concretan en las acciones que se comentan a continuación. En las opciones de búsqueda, libre o rápida, se ofrecerá además la consulta de los bienes de Patrimonio Mueble, con la opción adicional de realizar consultas conjuntas en Patrimonio Inmueble y Patrimonio Mueble.

Está prevista la incorporación de otras opciones que cualifiquen las búsquedas. Entre ellas cabe destacar la consulta en línea del Tesauro de Patrimonio Histórico para la búsqueda, consulta y captura de los términos incluidos en el Tesauro, presentando una relación alfabética de dichos términos y el número de total de registros que contienen dicho término. Esta opción se complementará con la incorporación de un Glosario que recoja los términos no incluidos en el Tesauro. Asimismo se plantea la ampliación de los operadores aplicables entre diferentes términos de un mismo campo (truncamiento, adyacencia).

Respecto a la recuperación de información se plantea añadir la opción Acumulado, que permite la consulta de los registros seleccionados o acumulados dentro de una sesión de búsqueda (con una o varias búsquedas), presentando los mismos datos que en la lista de resultados.

De gran interés se considera la incorporación progresiva de las Imágenes a la información textual de los bienes culturales, a través de la integración del banco de imágenes del IAPH a la aplicación de consulta de la BDI-PHA en Internet.

Por último, en el diseño del Portal de Patrimonio Histórico ${ }^{14}$, proyecto en desarrollo del 
Centro de Documentación, la sección Bases de Datos facilitará la consulta y acceso no sólo a la información de los bienes culturales andaluces como ya hemos comentado sino también a las fuentes de información del Patrimonio Histórico. Se incluirán las bases de datos propias y se ofrecerá el acceso a bases de datos sobre Patrimonio Histórico producidas por otros organismos, a través de enlaces establecidos con dichos recursos de información. Con ello, pretendemos ofrecer la integración de la información especializada sobre el Patrimonio Histórico a través de Internet.

\section{Notas}

I. Blanco, A., Madrid, V., Ortega, I. El Servicio de Información del Patrimonio Histórico de Andalucía: implantación y desarrollo. En: Actas de las VI Jornadas Españolas de Documentación. Valencia: FESABID, 1998. ISBN 84-33I-4609-X (obra completa)

2. Ortega, I., Limón, S. El Servidor Web del Instituto Andaluz del Patrimonio Histórico. En: Boletín del Instituto Andaluz del Patrimonio Histórico, año $\mathrm{V}, \mathrm{n}^{\circ}$ 19, junio 1997, pág. 139-146

3. Son varios los CD-Rom temáticos elaborados por el Centro de Documentación: Viviendas populares en Málaga, Inmuebles protegidos de las capitales andalu- zas, Megalitos de la provincia de Sevilla, Clausuras, Monasterios y Conventos de Cádiz, etc.

4. En la actualidad esta base de datos se denomina (DatARQUEOS).

Sánchez, F., Ortega, I., Díaz, J.M. Las bases de datos del Patrimonio Histórico Andaluz en el servidor web del IAPH. I ${ }^{\text {a }}$ fase: ARQUEOS. En: Boletín del Instituto Andaluz del Patrimonio Histórico, año VII, $n^{\circ} 29$, diciembre 1999, p. 216-219. ISSN II361867

5. A finales de año está prevista la culminación de la primera fase del Sistema Integrado del Patrimonio Histórico que está desarrollándose sobre Oracle y que incluirá información de Ciudades Históricas y Patrimonio Inmueble.

6. De momento sólo se han incluido algunas imágenes aunque está prevista la incorporación progresiva del banco de imágenes del IAPH.

7. En el Sistema Integrado está previsto que esa vinculación exista para todas las caracterizaciones.

8. García Gutiérrez, A. (Director): Tesauro de Patrimonio Histórico Andaluz. Versión 0. . Granada: Consejería de Cultura. Junta de Andalucía, 1998. Muñoz Cruz, V.: La normalización del Sistema de Información del Patrimonio Histórico de Andalucía: El Tesauro de Patrimonio Histórico. En: Boletín del Instituto Andaluz del Patrimonio Histórico, año IV, n 14, marzo 1996, pág. 110-115.

9. Tapia Martín, C.: Patrimonio Arquitectónico: la renovación del Sistema de Información SIBIA. En: Boletín del Instituto Andaluz del Patrimonio Histórico, año VII, n²8, septiembre 199, pág. 173-178.
10. La arquitectura defensiva se declaró de forma genérica en 1949 por esta razón la información existente en SIBIA sobre este tipo de arquitectura es muy escasa. Sin embargo desde DatARQUEOS sí se ha volcado a la nueva aplicación la arquitectura defensiva pues la información está más contrastada ya que se realizan revisiones periódicas del Inventario Arqueológico.

I I. Fernández, S.; Mondéjar, P.; Díaz, J.M. Arqueos: un modelo andaluz de gestión de la información arqueológica. En: Boletín del Instituto Andaluz del Patrimonio Histórico, año VIII, n 30, marzo 2000, pág. |43-149.

12. Hernández León, E;; Quintero Morón, V. El Patrimonio Etnológico en el sistema de Información del Patrimonio Histórico Andaluz. En: Boletín del Instituto Andaluz del Patrimonio Histórico, año Vl, n²3, junio 1998, pág. 117-121.

13. En la actualidad se está normalizando e informatizando el Inventario por este motivo la información a la que es posible acceder es muy básica. La información de Málaga es más completa pues esta provincia se informatizó para la elaboración de un CdRom de Viviendas Populares de esa provincia.

14. Ladrón de Guevara, C., Limón, S., Ortega, I. El Portal del Patrimonio Histórico de Andalucía. En: Boletín del Instituto Andaluz del Patrimonio Histórico, año VIII, n 33, diciembre 2000, pág. 205-2। I. ISSN I|36-1867

Valle Muñoz Cruz Isabel Ortega Vaquero Centro de Documentación del IAPH

\section{El Instituto de Patrimonio Cultural de Venezuela}

El Instituto de Patrimonio Cultural de Venezuela, el IPC, dispone de una completa a la vez que interesante página Web que refleja la labor que se realiza en dicha institución, y en general, el trabajo que se desarrolla en Venezuela a nivel gubernamental en lo relacionado con el Patrimonio Cultural.

Al realizar un recorrido por esta página, parece identificarse en numerosas ocasiones la huella de la Web del IAPH, concretamente de su Centro de Documentación, no tanto en lo tocante al diseño como en lo relativo a los contenidos. Es probable que la propia institución, el Instituto de Patrimonio Cultural Venezolano se haya inspirado en ocasiones o haya tomado como modelo la labor previamente realizada por el Instituto Andaluz de Patrimonio Histórico. No obstante, el IPC en Internet cuenta con evidentes aportaciones novedosas que se señalarán en este artículo.
Los pilares sobre los que se asientan los contenidos de esta página figuran en un menú que permanece fijo a la izquierda de la pantalla a lo largo de todo el recorrido por la Web. Entre los botones de este menú se encuentran Home, la página inicial, Acerca del IPC, una presentación o introducción al Instituto, Centro de Documentación, Bases de datos o Bienes Culturales Declarados, a los que se dedica una parte muy importante de la página Web y que se describirán más adelante, así como una serie de ejemplos concretos de elementos del Patrimonio con imágenes y descripciones.

El resto del menú nos permite acceder a los Proyectos del IPC, al Catálogo de Publicaciones y a las Publicaciones electrónicas, y a los Eventos, Noticias y Sitios de interés.

El Centro de Documentación se encarga de realizar todas las tareas que abarcan desde la selección y adquisición hasta la difusión de informa- ción relacionada con la protección del Patrimonio Cultural venezolano. Cuenta con fuentes documentales relativas a la conservación del patrimonio, fundamentalmente bibliográficas y fotográficas, así como con las bases de datos de los distintos inventarios de patrimonio.

El Centro de Documentación desarrolla el Proyecto de Inventario Nacional, integrado por diversas bases de datos temáticas que recogen toda la información registrada hasta el momento por la institución sobre los bienes integrantes del patrimonio cultural del país.

Entre estas bases de datos, el Preinventario de los Bienes Culturales y el Inventario de Testimonios y Procesos Culturales están disponibles en línea y permiten el acceso libre a la información que contienen a través de Internet.

Por otro lado, existen otras bases de datos que por el momento únicamente pueden con- 